\title{
Separation Studies of Pd(II) from Acidic Chloride Solutions of Pt(IV), Ni(II) and Rh(III) by Using 4-Aroyl-3-Phenyl-5-Isoxazolones
}

\author{
KODURU JANARDHAN REDDY ${ }^{1,2}$ and LEE KAP DUK ${ }^{1 \dagger}$ \\ ${ }^{1}$ Department of Nanomaterial Chemistry \\ College of Science \& Technology, Dongguk University \\ 707 Seokjang-Dong, Gyeongju, Gyeongbuk -780 714, Republic of Korea \\ ${ }^{2}$ Department of Chemistry (GEBH) \\ Sreevidyanikethan Engineering College (Atonomous), Sri Sainath Nagar-517 501 \\ A.Rangampet, Tirupathi, Andhrapradesh, India \\ kapduklee1@gmail.com,kdlee@dongguk.ac.kr
}

Received 25 October 2011; Accepted 30 December 2011

\begin{abstract}
This study examined the effect influence of various factors on the extraction of $\mathrm{Pd}(\mathrm{II})$ to develop a new liquid-liquid extraction mechanism for the selective separation of palladium(II) from its acidic chloride solutions using 4-aroyl-3-phenyl-5-isoxazolones (HA), such as 3-phenyl-4-(4-fluorobenzoyl)-5isoxazolone (HFBPI), 3-phenyl-4-benzoyl-5-isoxazolone (HPBI) and 3-phenyl-4(4-toluoyl)-5-isoxazolone (HTPI). The extraction strength of Pd(II) with HA were in the following order: HFBPI > HPBI > HTPI, which is opposite to that observed with their $\mathrm{p} K_{\mathrm{a}}$ values. HPBI was used to separate $\mathrm{Pd}(\mathrm{II})$ from $\mathrm{Pt}(\mathrm{IV}), \mathrm{Ni}(\mathrm{II})$ and $\mathrm{Rh}$ (III) metal ions and calculated their separation factors (S.F.) were followed in the order: $\mathrm{Pd} / \mathrm{Ni}(40 \pm 0.4)>\mathrm{Pd} / \mathrm{Pt}(25 \pm 0.2)>\mathrm{Pd} / \mathrm{Rh}(15 \pm 0.3>\mathrm{Rh} / \mathrm{Ni}(2.7 \pm 0.3)>\mathrm{Pt} / \mathrm{Ni}$ $\approx \mathrm{Rh} / \mathrm{Pt}(1.7 \pm 0.2)$. The loading and striping of $\mathrm{Pd}(\mathrm{II})\left(1.12 \times 10^{-4} \mathrm{~mol} \mathrm{~L}^{-1}\right)$ were also examined using $1.0 \times 10^{-3} \mathrm{~mol} \mathrm{~L}^{-1} \mathrm{HPBI}$ in $\mathrm{CHCl}_{3}$ and $1.0 \mathrm{~mol} \mathrm{~L}^{-1} \mathrm{HCl}$, respectively. The results demonstrated that the maximum $(97.5 \%)$ extraction and desorption $(89 \%)$ of metal required at least 3.0 cycles. The developed method was applied successfully to the separation of palladium from synthetic water samples.
\end{abstract}

Keywords: Palladium(II) extraction, Separation of precious metals, 4-Aroyl-3-phenyl-5-isoxazolones, Acidic chloride solutions.

\section{Introduction}

Palladium group metals (PGMs) are used widely as catalysts in hydrogenation reactions in chemical and automobile industries as well as in other organic syntheses ${ }^{1,2}$. These materials are extremely useful in areas, such as electrical and electronic industries, extrusion devices, in jewelry and dental and medical prostheses, owing to their high resistance to corrosion and oxidation with high melting points, electrical conductivity and catalytic activity ${ }^{1-3}$. In 
addition, they are extremely important to the automotive industry because there is no other metal substitute for PGMs.

Despite the limited supply of primary sources and limited availability for industry ${ }^{3,4}$, the demand for PGMs is increasing continuously. Therefore, the recovery or recycling of PGMs from secondary resources or from post-consumer scrap is needed to secure these metals. The major secondary resource of PGMs is spent automobile catalysts and nuclear waste but the amount of PGMs currently being recycled from spent auto catalyst is only $\sim 20 \%$, An efficient and selective extraction/separation technique is essential for the recycling of PGMs from secondary resources.

There are some conventional methods for the separation of the $\mathrm{PGMs}^{3}$ but they have inherent problems, such as high chemical consumption and high labor requirements in the procuring process, slow kinetics, solid-liquid separation and increased environmental pollution due to the use of toxic chemicals. In addition, the aqueous chemistry of these metals is extremely complicated ${ }^{7-10}$. Therefore, it is important to develop a feasible hydrometallurgical route in the place of the above conventional methods.

Liquid-liquid extraction is a versatile technique for the separation/concentration of metal species from aqueous solutions and has also been used commercially in to separate palladium/platinum using several extractants ${ }^{9-13}$. Nevertheless, there are limitations, such as poor selectivity and difficult stripping. Recently, 4-aroyl-5-isoxazolones have been used to separate $\mathrm{Zr}(\mathrm{IV})$ and $\mathrm{Hf}(\mathrm{IV})$ and some other lanthanides and actinides from its acidic solutions with good selectivity between these metal ions ${ }^{14-19}$.

The above factors prompted us to develop a selective liquid-liquid extraction method for the extraction of palladium from its acidic chloride solutions using 4-aroyl derivates of 3-phenyl-5isoxazolones (HA) (Figure 1). Specifically, 3-phenyl-4-(4-fluorobenzoyl)-5-isoxazolone (HFBPI), 3-phenyl-4-benzoyl-5-isoxazolone (HPBI) and 3-phenyl-4-(4-toluoyl)-5-isoxazolone (HTPI), were synthesized ${ }^{14,15}$ by introducing both electron-withdrawing (-F) and electrondonating $\left(-\mathrm{CH}_{3}\right)$ groups and their effects on the extraction behavior of $\mathrm{Pd}(\mathrm{II})$ from hydrochloric acid solutions was investigated. In addition, a range of factors, such as the extractant concentration in the organic phase and the acid and chloride concentration in the aqueous phase, were examined to achieve a better selectivity of Pd(II) from Pt(IV), Ni(II) and Rh(III) metal ions.

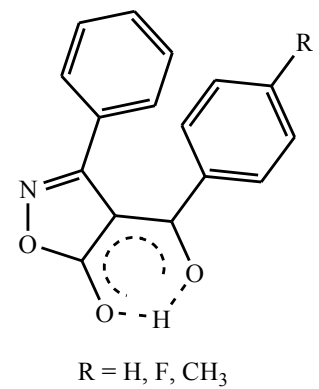

Figure 1. 4-Aroyl-3-phenyl-5-isoxazolones (HA).

\section{Experimental}

A Varian SpectrAA 220 (AAS) (Varian Australia Pty., Ltd., Australia) was used to determine the metal ion concentrations in aqueous solutions. An Orion (USA) 720A Ion Analyzer was used for the $\mathrm{pH}$ measurements. A Nicolet FT-IR 560 Magna spectrometer using $\mathrm{KBr}$ (neat) was used to obtain the infrared spectra of the synthesized ligands. $\mathrm{C}, \mathrm{H}$ and $\mathrm{N}$ analysis were 
performed using a Perkin-Elmer Series 2 Elemental Analyzer 2400. A Bruker $300 \mathrm{MHz}$ NMR spectrometer was used to obtain the ${ }^{1} \mathrm{H}$ NMR spectra of the isoxazolones.

\section{Chemicals}

Palladium and platinum stock solutions were prepared using $\mathrm{PdCl}_{2}$ (Analytical reagent, 99\%) and $\mathrm{PtCl}_{4}$ (Analytical reagent, 99\%), which were purchased from Sigma Aldrich Chemical Company Pvt. Ltd., Republic of Korea. $\mathrm{NiCl}_{2} \cdot 6 \mathrm{H}_{2} \mathrm{O}$ (Merck, 98\%) and $\mathrm{RhCl}_{3} \cdot \mathrm{nH}_{2} \mathrm{O}$ (Merck, 98.5\%) were used to prepare the respective metal ion stock solutions. Suitably diluted stock solutions of metal ions were used in the extraction and analytical studies. The ionic strength was maintained at $1.0 \mathrm{~mol} \mathrm{~L}^{-1}$ using sodium chloride and hydrochloric acid (Analytical reagent, Merck, Korea). Chloroform (Analytical reagent, Merck, Republic of Korea) was used as the diluent. All other chemicals used were of analytical reagent grade.

\section{Synthesis and characterization of various 3-phenyl-4-aroyl-5-isoxazolones}

The synthesis of the various 4-aryol-3-phenyl-5-isoxazolones using Scheme 1 and 2 is reported elsewhere ${ }^{14-16}$. The synthesis of the ligands and their characterizations are shown below:

\section{3-Phenyl-4-benzoyl-5-isoxazolone (HPBI)}

HPBI was synthesized by the benzoylation of 3-phenyl-5-isoxazolone (Scheme 1) ${ }^{14-16}$. 3-Phenyl5-isoxazolone, benzoic anhydride and sodium benzoate were refluxed in dry 1, 4-dioxane for $3 \mathrm{~h}$. The reaction mixture was cooled and filtered. The filtrate was diluted with distilled water and acidified with $\mathrm{HCl}$. The brown precipitate was filtered, dried and recrystallized from ethyl acetate. FT-IR, ${ }^{1} \mathrm{H}$ NMR and elemental analysis were used for characterization.

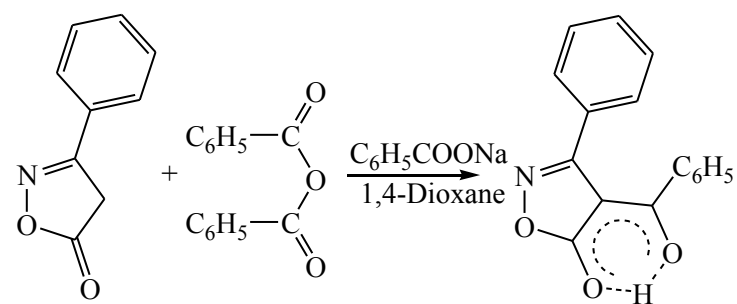

Scheme 1. Synthesis of 3-phenyl-4-benzoyl-5-isoxazolone (HPBI).

HPBI : M.P. $=146{ }^{\circ} \mathrm{C} ;{ }^{1} \mathrm{H}$ NMR data: $\delta 6.94-8.06$ (m, 10H, phenyl); IR (KBr) data $\left(\mathrm{v} \mathrm{cm}^{-1}\right): 3052,1699,1613,1489,831$; Elemental analysis: Calc. for $\mathrm{C}_{16} \mathrm{H}_{11} \mathrm{NO}_{3}, \mathrm{C}, 72.45$; H,4.15; N, 5.28. Found: C, 72.27; H, 4.18; N, 5.17\%.

\section{3-Phenyl-4-aroyl-5-isoxazolones}

3-Phenyl-4-(4-fluorobenzoyl)-5-isoxazolone (HFBPI) and 3-phenyl-4-(4-toluoyl)-5isoxazolone (HTPI) were synthesized from 3-phenyl-5-isoxazolone and the corresponding acid chlorides (Scheme 2) ${ }^{14-16}$. The crude products were filtered, dried and recrystallized from ethyl acetate. The synthesized 4-aroyl-3-phenyl-5-isoxazolones were confirmed by FT-IR, ${ }^{1} \mathrm{H}$ NMR and elemental analysis.

HTPI : M.P. $=145{ }^{0} \mathrm{C} ;{ }^{1} \mathrm{H}$ NMR (Figure S2) data: $\delta$ 6.93-7.37 (m, 9H, phenyl); 2.31 (3H, methyl); IR data $\left(\mathrm{v} \mathrm{cm}^{-1}\right): 2600,1699,1613,1600,830$; Elemental analysis: Calc. for $\mathrm{C}_{17} \mathrm{H}_{13} \mathrm{NO}_{3}, \mathrm{C}, 73.12 ; \mathrm{H}, 4.66 ; \mathrm{N}, 5.02$. Found: $\mathrm{C}, 73.52 ; \mathrm{H}, 4.73 ; \mathrm{N}, 5.31 \%$. 


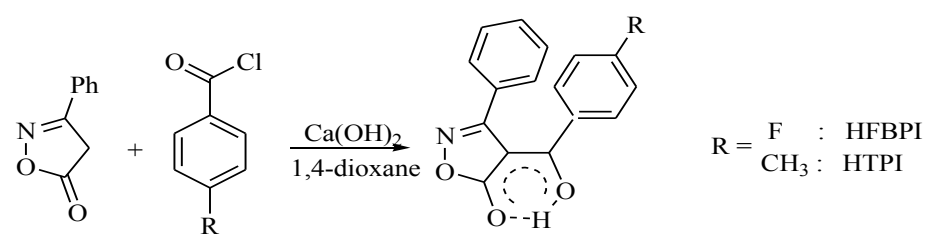

Scheme 2. Synthesis of 3-phenyl-4-aroyl-5-isoxazolones.

HFBPI : M.P. $=149{ }^{0} \mathrm{C} ;{ }^{1} \mathrm{H}$ NMR data: $\delta 6.80-7.40\left(\mathrm{~m}, 9 \mathrm{H}\right.$, phenyl); IR data $\left(\mathrm{v} \mathrm{cm}^{-1}\right)$ : 2600, 1702, 1620, 1583; Elemental analysis: Calc. for $\mathrm{C}_{16} \mathrm{H}_{10} \mathrm{NO}_{3} \mathrm{~F}, \mathrm{C}, 67.84 ; \mathrm{H}, 3.53 ; \mathrm{N}$, 4.95. Found: C, 67.56; H, 4.08; N, 4.95\%.

The enolic -OH peaks observed at $\delta 5.90,4.08$ and 3.57 in the ${ }^{1} \mathrm{H}$ NMR spectra of HPBI, HTPI and HFBPI, respectively, were found to be exchanged upon the addition of $\mathrm{D}_{2} \mathrm{O},{ }^{14}$ which confirms the existence of these compounds in the enolic form. The absence of a peak at $\delta 3.8$ corresponding to the methylene proton at the fourth position of the isoxazolone ring, further confirmed the existence of various 3-phenyl-4-aroyl-5-isoxazolones quantitatively in enolic form.

\section{Liquid- liquid extraction and analytical procedure}

Equal volumes of aqueous and organic phases were placed in a glass stopper vial and shaken for 45 min using a mechanical shaker at $303 \pm 1.0 \mathrm{~K}$ to determine the distribution of metal ions. The solutions were allowed to settle and the phases were separated. The $\mathrm{Pd}(\mathrm{II})$ concentration in the aqueous phase was determined using AAS. The concentration of metal ions in the organic phase was then obtained by mass balance. The distribution ratio, $D$ was taken as the ratio of the concentration of metal ions in the organic phase to that in the aqueous phase. All experiments were performed in duplicate and the general agreement between the distribution ratios values obtained was within $\pm 5 \%$. Chloroform was chosen as the diluent due to the solubility limitations of 4-aroyl-3-phenyl-5-isoxazolones in various industrially employed diluents. The ionic strength was maintained at $1.0 \mathrm{~mol} \mathrm{~L}^{-1}$ using a sodium chloride and hydrochloric acid mixture.

\section{Results and Discussion}

Liquid-liquid extraction of Pd(II) from its acidic chloride solutions using 4-aroyl-3phenyl-5-isoxazolones (HA)

The metal ion distribution equilibrium studies were performed using equal volumes of the aqueous phase $\left(1.12 \times 10^{-4} \mathrm{~mol} \mathrm{~L}^{-1}\right.$ of $\mathrm{Pd}(\mathrm{II})$ at $0.1 \mathrm{~mol} \mathrm{~L}^{-1}\left[\mathrm{H}^{+}\right]$and $1.0 \mathrm{~mol} \mathrm{~L}^{-1} \mathrm{Cl}^{-}$was maintained using $\mathrm{HCl}+\mathrm{NaCl}$ mixture) and organic phase $\left(1.0 \times 10^{-3} \mathrm{~mol} \mathrm{~L}^{-1} \mathrm{HA}\right.$ in Chloroform) at $303 \pm 1.0 \mathrm{~K}$. The results obtained are shown in Figure 2. The maximum time needed to reach the maximum metal ion extraction into the organic phase was 30 to $45 \mathrm{~min}$. Therefore, further studies were performed for $45 \mathrm{~min}$, which is said to be a sufficient equilibration time for $\mathrm{Pd}(\mathrm{II})$ extraction into the organic phases.

The effect of 4-aroyl-3-phenyl-5-isoxazolone (HA) (3-phenyl-4-benzoyl-5-isoxazolone (HPBI), 3-phenyl-4-(4-fluorobenzoyl)-5-isoxazolone (HFBPI) and 3-phenyl-4-(4-toluoyl)-5isoxazolone (HTPI) ) concentrations $\left(1.0 \times 10^{-3}-3.0 \times 10^{-3} \mathrm{~mol} \mathrm{~L}^{-1}\right.$ in chloroform) on the extraction behavior of $\mathrm{Pd}(\mathrm{II})$ was investigated at constant metal ion $\left(1.12 \times 10^{-4} \mathrm{~mol} \mathrm{~L}^{-1}\right)$ and hydrochloric acid $\left(0.05 \mathrm{~mol} \mathrm{~L}^{-1}\right)$ concentrations, and the results are depicted in Figure 3 . The extraction of metal ions increased linearly with increasing 4-aroyl-3-phenyl-5-isoxazolone concentration. The log-log plots gave slopes of $2.0 \pm 0.22$, indicating the involvement of two molecules of extractant in complex formation. 


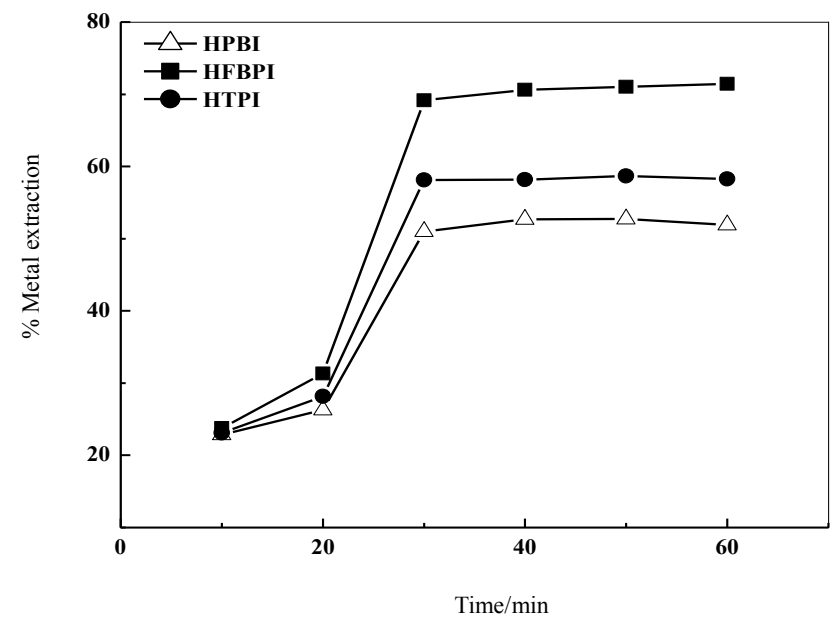

Figure 2. Kinetic equilibrium of $\mathrm{Pd}(\mathrm{II})$ with 4-aroyl-3-phenyl-5-isoxazolones(HA). [HA] = $1.0 \times 10^{-3} \mathrm{~mol} \mathrm{~L}^{-1}, \mathrm{Pd}(\mathrm{II})=1.12 \times 10^{-4} \mathrm{~mol} \mathrm{~L}^{-1}$ at $0.1 \mathrm{~mol} \mathrm{~L}^{-1} \mathrm{H}^{+}$and $1.0 \mathrm{~mol} \mathrm{~L}^{-1} \mathrm{Cl}^{-}$.

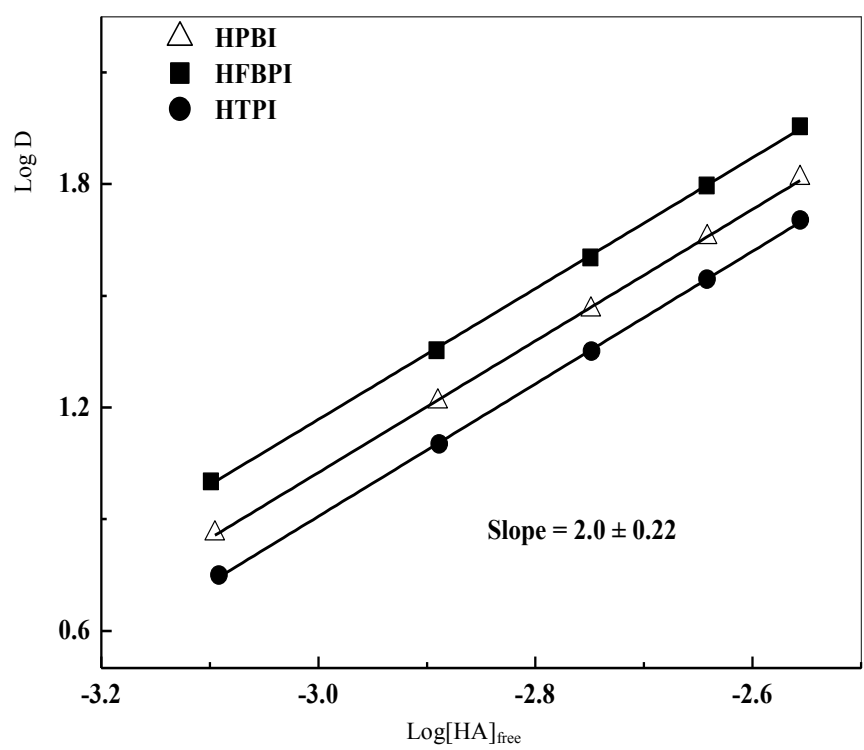

Figure 3. Effect of 4-aroyl-3-phenyl-5-isoxazolones (HA) on $\mathrm{Pd}(\mathrm{II})$ extraction. Aqueous phase $=1.12 \times 10^{-4} \mathrm{~mol} \mathrm{~L}^{-1} \mathrm{Pd}(\mathrm{II})$ at $0.1 \mathrm{~mol} \mathrm{~L}^{-1} \mathrm{H}^{+}$and $1.0 \mathrm{~mol} \mathrm{~L}^{-1} \mathrm{Cl}^{-}$, Organic phase $=$ $1.0 \times 10^{-3} \mathrm{~mol} \mathrm{~L}^{-1}$ in $\mathrm{CHCl}_{3}$, Equilibration time $=45 \mathrm{~min}$.

The extraction of Pd(II) with HPBI, HFBPI and HTPI $\left(1.0 \times 10^{-3} \mathrm{~mol} \mathrm{~L}^{-1}\right)$ in chloroform was examined as a function of the hydrogen ion concentration at constant metal $\left(1.12 \times 10^{-4} \mathrm{~mol} \mathrm{~L}^{-1}\right)$ and chloride ion $\left(1.0 \mathrm{~mol} \mathrm{~L}^{-1}\right)$ concentrations by employing $\mathrm{HCl}$ and $\mathrm{NaCl}$ mixtures. The extraction behavior showed an inverse dependence on acidity. The log-log plots (Figure 4) gave slopes of $-2.0 \pm 0.11$, indicating the release of two hydrogen ions into the aqueous phase. The effect of the chloride ion concentration $\left(0.1\right.$ to $\left.1.0 \mathrm{~mol} \mathrm{~L}^{-1}\right)$ was also studied using a $\mathrm{NaCl}$ and $\mathrm{HCl}$ mixture at $0.05 \mathrm{~mol} \mathrm{~L}^{-1}\left[\mathrm{H}^{+}\right]$. The results showed that the extraction/ distribution of $\mathrm{Pd}(\mathrm{II})$ ion is independent of the chloride ion concentration. 


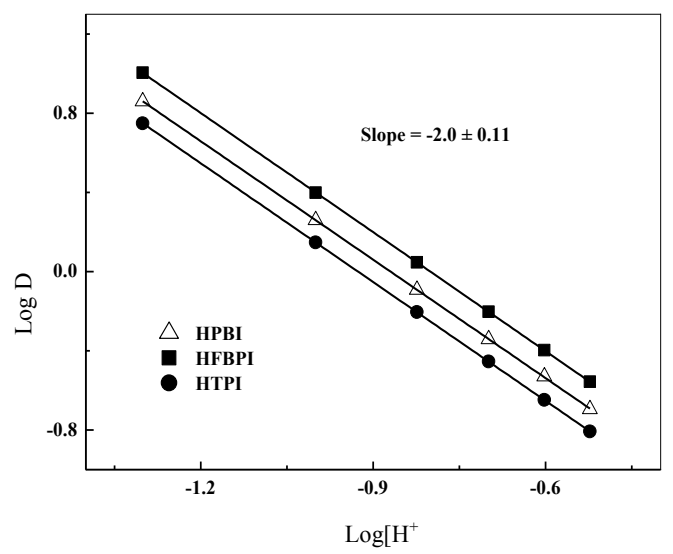

Figure 4. Effect of the $\mathrm{H}^{+}$concentration on $\mathrm{Pd}(\mathrm{II})$ extraction with 4-aroyl-3-phenyl-5isoxazolones(HA). Aqueous phase $=1.12 \times 10^{-4} \mathrm{~mol} \mathrm{~L}^{-1} \mathrm{Pd}(\mathrm{II})$ at $1.0 \mathrm{~mol} \mathrm{~L}^{-1}$ ionic strength, Organic phase $=1.0 \times 10^{-3} \mathrm{~mol} \mathrm{~L}^{-1}$ in $\mathrm{CHCl}_{3}$, Equilibration time $=45 \mathrm{~min}$.

The effect of the metal ion concentration $\left(0.5 \times 10^{-4}-2.8 \times 10^{-4} \mathrm{~mol} \mathrm{~L}^{-1}\right)$ on the extraction process of $\mathrm{Pd}(\mathrm{II})$ from $0.05 \mathrm{~mol} \mathrm{~L}^{-1}$ hydrochloric acid solutions was examined using a range of 4-aroyl-3-phenyl-5-isoxazolones $\left(1.0 \times 10^{-3} \mathrm{~mol} \mathrm{~L}^{-1}\right)$ in chloroform. The results showed that extraction is independent of the metal ion concentration in the range investigated.

The log-log plots (Figure 5) of the equilibrium organic phase metal concentrations as a function of the aqueous phase metal concentrations were linear with slopes of unity, indicating the extraction of mononuclear species into the organic phase. Based on these results, the extraction equilibrium of $\mathrm{Pd}(\mathrm{II})$ from hydrochloric acid solutions with 4-aroyl-3phenyl-5-isoxazolones (HA) can be represented as follows:

$$
\mathrm{Pd}_{\mathrm{aq}}^{2+}+2 \mathrm{HA}_{\text {org }} \stackrel{\boldsymbol{K}_{\text {ex,Pd(II) }}}{\rightleftharpoons} \mathrm{Pd}^{2+} \mathrm{A}_{2 \text { org }}+2 \mathrm{H}^{+}{ }_{\text {aq }}
$$

Where $K_{\text {ex, Pd(II) }}$ denotes the conditional equilibrium constant and can be expressed as:

$$
\boldsymbol{K}_{\text {ex,Pd(II) }}=\frac{\left[\mathrm{Pd}^{2+} \mathrm{A}_{2}\right]_{\mathrm{org}}\left[\mathrm{H}^{+}\right]_{\mathrm{aq}}^{2}}{\left[\mathrm{Pd}^{2+}\right]_{\mathrm{aq}}[\mathrm{HA}]_{\mathrm{org}}^{2}}
$$

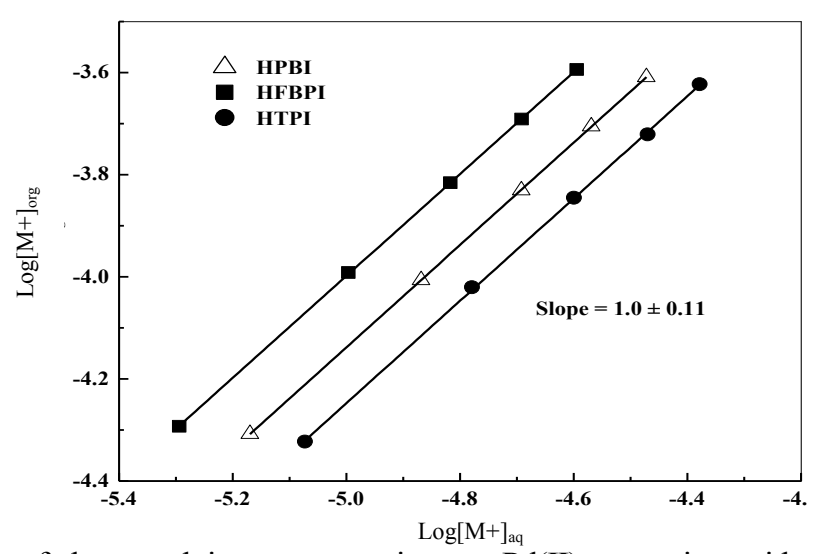

Figure 5. Effect of the metal ion concentration on Pd(II) extraction with 4-aroyl-3-phenyl-5isoxazolones(HA). Aqueous phase $=0.5 \times 10^{-4}-2.8 \times 10^{-4} \mathrm{~mol} \mathrm{~L}^{-1} \mathrm{Pd}(\mathrm{II})$ at $0.05 \mathrm{~mol} \mathrm{~L}^{-1} \mathrm{H}^{+}$and $1.0 \mathrm{~mol} \mathrm{~L}^{-1}$ ionic strength, Organic phase $=1.0 \times 10^{-3} \mathrm{~mol} \mathrm{~L}^{-1}$ in $\mathrm{CHCl}_{3}$, Equilibration time $=45 \mathrm{~min}$. 
The calculated $K_{\text {ex,Pd(II) }}$ values refer only to the concentration quotients, which are calculated based on the assumption that the activity coefficients of the species involved do not change significantly under the present experimental conditions. Table 1 lists the equilibrium constants of $\mathrm{Pd}(\mathrm{II})$ with various 4-aroyl-3-phenyl-5-isoxazolones. A comparison of the equilibrium constants of various 4-aroyl-3-phenyl-5-isoxazolones with their $\mathrm{p} K_{\mathrm{a}}$ value ${ }^{14,17-20}$ showed that the equilibrium constants increase with decreasing $\mathrm{p} K_{\mathrm{a}}$ of HA. This shows that the extraction efficiency of Pd(II) ions occurs in the following order HFBPI $>$ HPBI > HTPI. Interestingly, the substitution of electron-withdrawing fluorine in the fourth position of the benzoyl moiety in the HPBI molecule improves the extraction efficiency of these metal ions. On the other hand, the substitution of an electron-releasing, e.g. like methyl $\left(-\mathrm{CH}_{3}\right)$, reduces the extraction efficiency. Therefore, it is clear from the present study that the extraction of $\mathrm{Pd}(\mathrm{II})$ with 4-aroyl-3-phenyl-5-isoxazolone vary in accordance with the substituent on the benzoyl moiety of isoxazolone, which ultimately reflects the acidity of the ligand $\left(\mathrm{p} K_{\mathrm{a}}\right)$, which was supported by other reports ${ }^{14,15}$.

Table 1. Relationship between the extractant $\mathrm{p} K_{\mathrm{a}}$ and equilibrium constants of $\mathrm{Pd}(\mathrm{II})$ towards its extraction from acidic chloride solutions using isoxazolones in chloroform.

\begin{tabular}{ccc}
\hline Extractant & $\mathrm{p} K_{\mathrm{a}}$ & $\log K_{\text {ex }, \text { Pd(II) }}$ \\
\hline HFBPI & 0.65 & $4.39 \pm 0.06$ \\
HPBI & 1.23 & $4.26 \pm 0.05$ \\
HTPI & 1.48 & $4.15 \pm 0.04$ \\
\hline
\end{tabular}

\section{Loading and striping studies of 4-aroyl-3-phenyl-5-isoxazolones (HA)}

Loading and striping studies of 4-aroyl-3-phenyl-5-isoxazolones were performed using HPBI $\left(1.0 \times 10^{-3} \mathrm{~mol} \mathrm{~L}^{-1}\right)$ as a representative of the above working isoxazolones. $1.12 \times 10^{-4} \mathrm{~mol} \mathrm{~L}^{-1}$ $\mathrm{Pd}(\mathrm{II})$ at $0.05 \mathrm{~mol} \mathrm{~L}^{-1} \mathrm{H}^{+}$and $1.0 \mathrm{~mol} \mathrm{~L}^{-1} \mathrm{HCl}$ were used for the loading and striping studies of $\mathrm{Pd}(\mathrm{II})$, respectively and are shown in Figure 6 . The results show that the maximum loading $(97.5 \%)$ and striping $(89 \%)$ of $\mathrm{Pd}(\mathrm{II})$ was within 3.0 cycles of the above experiments.

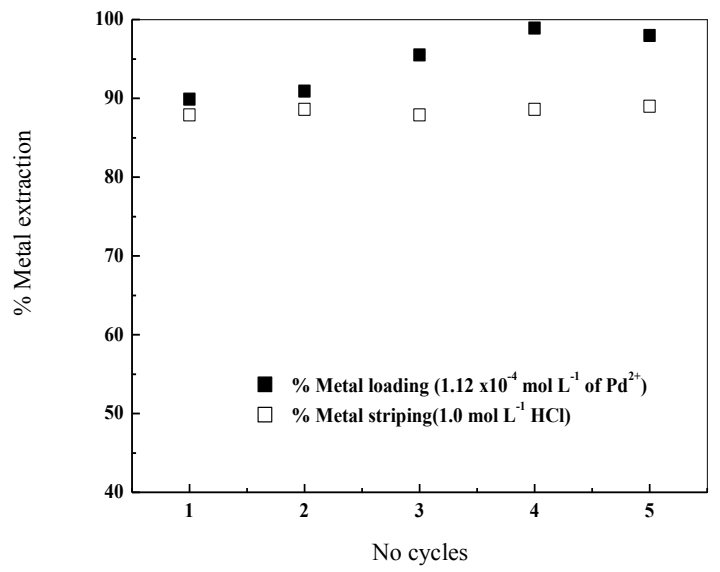

Figure 6. Loading and striping studies of Pd(II) with HPBI. Conditions for extraction = $1.12 \times 10^{-4} \mathrm{~mol} \mathrm{~L}^{-1} \mathrm{Pd}(\mathrm{II})$ in $0.05 \mathrm{~mol} \mathrm{~L}^{-1} \mathrm{H}^{+}$at $1.0 \mathrm{~mol} \mathrm{~L}^{-1} \mathrm{Cl}^{-}, 1.0 \times 10^{-3} \mathrm{~mol} \mathrm{~L}^{-1} \mathrm{HPBI}$ in $\mathrm{CHCl}_{3}$; Conditions for desorption $=1.0 \mathrm{~mol} \mathrm{~L}^{-1} \mathrm{HCl}$. 
Separation of Pd(II) from acidic chloride solutions of Pt(IV), Ni(II) and Rh(II)

The separation of $\mathrm{Pd}(\mathrm{II})$ from $\mathrm{Pt}(\mathrm{IV}), \mathrm{Ni}(\mathrm{II})$ and $\mathrm{Rh}(\mathrm{III})$ ions present in acidic chloride solutions were examined as a function of $\left[\mathrm{H}^{+}\right]\left(0.05-0.3 \mathrm{~mol} \mathrm{~L}^{-1}\right)$ and $[\mathrm{HPBI}]\left(1.0 \times 10^{-3} \mathrm{~mol} \mathrm{~L}^{-1}\right)$ and the results shown in Figure 7 and 8 . The results show that metal extraction decreases linearly with increasing $\mathrm{H}^{+}$ion concentration and $\mathrm{Pd}(\mathrm{II})$ shows maximum extraction at $0.05 \mathrm{~mol} \mathrm{~L}^{-1}\left[\mathrm{H}^{+}\right]$, with minimum extraction $(<35 \%)$ of the remain metal ions. An increase in the HPBI concentration results in an increase in metal ion extraction and showed $99 \%$ $\operatorname{Pd}(\mathrm{II})$ extraction at $3.0 \times 10^{-3} \mathrm{~mol} \mathrm{~L}^{-1}$, whereas $<75 \%$ metal extraction was achieved by remaining desired metal ions.

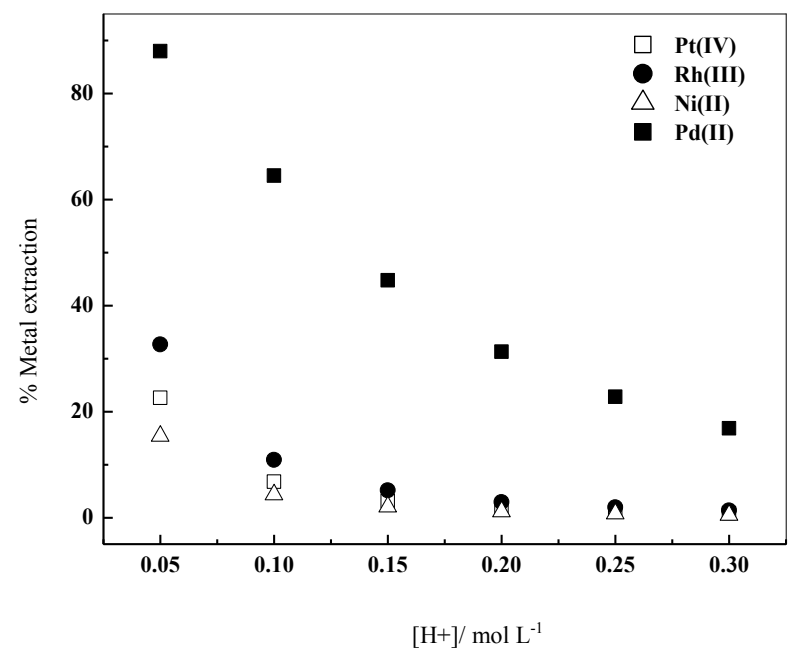

Figure 7. Separation studies of $\mathrm{Pd}(\mathrm{II})$ from acidic chloride solutions of $\mathrm{Pt}(\mathrm{IV}), \mathrm{Ni}(\mathrm{II})$ and $\mathrm{Rh}(\mathrm{III})$ as a function of the $\mathrm{H}^{+}$concentration using $\mathrm{HPBI}$ as extractant. $[\mathrm{M}]=1.12 \times 10^{-4} \mathrm{~mol} \mathrm{~L}^{-1}$ at $0.05 \mathrm{~mol} \mathrm{~L}^{-1} \mathrm{H}^{+}$with $1.0 \mathrm{~mol} \mathrm{~L}{ }^{-1} \mathrm{Cl}^{-},[\mathrm{HPBI}]=1.0 \times 10^{-3} \mathrm{~mol} \mathrm{~L}^{-1}$ in $\mathrm{CHCl}_{3}$.

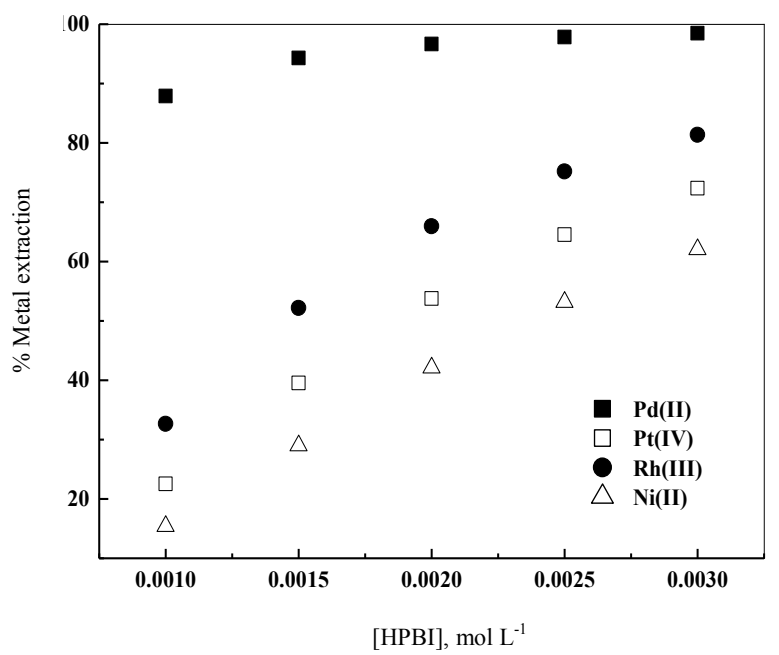

Figure 8. Separation studies of $\mathrm{Pd}(\mathrm{II})$ from acidic chloride solutions of $\mathrm{Pt}(\mathrm{IV}), \mathrm{Ni}(\mathrm{II})$ and $\mathrm{Rh}(\mathrm{III})$ as a function of the HPBI concentration. $[\mathrm{M}]=1.12 \times 10^{-4} \mathrm{~mol} \mathrm{~L}^{-1}$ at $0.05 \mathrm{~mol} \mathrm{~L}^{-1} \mathrm{H}^{+}$ with $1.0 \mathrm{~mol} \mathrm{~L}^{-1} \mathrm{Cl}^{-}$. 
Table 2 lists the separation factors of these metal ions calculated from their distribution ratios $(D)$, which were obtained from the extraction of metal ions $\left(1.12 \times 10^{-4} \mathrm{~mol} \mathrm{~L}^{-1}\right)$ at $0.05 \mathrm{~mol} \mathrm{~L}^{-1} \mathrm{H}^{+}$with various concentration of HPBI in chloroform. The results show that the selective separation of $\mathrm{Pd}(\mathrm{II})$ from the desired metal ions was achieved, particularly in the case of $\mathrm{Pd}(\mathrm{II})$ and $\mathrm{Ni}(\mathrm{II})$. Moreover, better separation $(\mathrm{Pd} / \mathrm{Ni}=40.0 \pm 0.30)$ was achieved.

Table 2. Separation of $\mathrm{Pd}(\mathrm{II})$ from $\mathrm{Pt}(\mathrm{IV}), \mathrm{Rh}(\mathrm{III}), \mathrm{Ni}(\mathrm{II})\left(1.12 \times 10^{-4} \mathrm{~mol} \mathrm{~L}^{-1}\right)$ chloride $\left(0.05 \mathrm{~mol} \mathrm{~L}^{-1} \mathrm{H}^{+}\right)$solutions using HPBI.

\begin{tabular}{ccccccccccc}
\hline HPBI/ & \multicolumn{4}{c}{$D$} & \multicolumn{7}{c}{ Average Separation Factors } \\
\cline { 2 - 10 } $\mathrm{mol} \mathrm{L}^{-1}$ & $\mathrm{Pd}(\mathrm{II})$ & $\mathrm{Pt}(\mathrm{IV})$ & $\mathrm{Rh}(\mathrm{III})$ & $\mathrm{Ni}(\mathrm{II})$ & $\mathrm{Pd} / \mathrm{Pt}$ & $\mathrm{Pd} / \mathrm{Rh}$ & $\mathrm{Pd} / \mathrm{Ni}$ & $\mathrm{Pt} / \mathrm{Ni}$ & $\mathrm{Rh} / \mathrm{Ni}$ & $\mathrm{Rh} / \mathrm{Pt}$ \\
\hline 0.001 & 7.268 & 0.291 & 0.485 & 0.182 & & & & & & \\
0.0015 & 16.452 & 0.654 & 1.0902 & 0.409 & $25.0 \pm$ & $15.0 \pm$ & $40.0 \pm$ & $1.70 \pm$ & $2.70 \pm$ & $1.70 \pm$ \\
0.002 & 29.072 & 1.163 & 1.938 & 0.727 & 0.22 & 0.15 & 0.30 & 0.40 & 0.35 & 0.42 \\
0.0025 & 45.43 & 1.817 & 3.028 & 1.136 & & & & & & \\
0.003 & 65.46 & 2.616 & 4.361 & 1.635 & & & & & & \\
\hline
\end{tabular}

The separation factors of among these metal ions were in the following order: $\mathrm{Pd} / \mathrm{Ni}>$ $\mathrm{Pd} / \mathrm{Pt}>\mathrm{Pd} / \mathrm{Rh}>\mathrm{Rh} / \mathrm{Ni}>\mathrm{Pt} / \mathrm{Ni} \approx \mathrm{Rh} / \mathrm{Pt}$, which can be explained by their ionic radius as well as by the hard and soft acid and base theory of metal ions. $\mathrm{Pd}(\mathrm{II})$ has a smaller ionic radius than $\mathrm{Ni}(\mathrm{II})$ and slightly more hardness than $\mathrm{Pt}(\mathrm{IV})$. Rh(III) ions were extracted more effectively using a hard ligand, $\mathrm{HPBI}^{19}$.

\section{Application and validity of the present liquid-liquid extraction method}

The developed method was applied to the separation and determination of $\mathrm{Pd}(\mathrm{II})$ in synthetic water samples. Various amounts of palladium $\left(0.012 \mathrm{~g} \mathrm{~L}^{-1}\right.$ to $\left.0.03 \mathrm{~g} \mathrm{~L}^{-1}\right)$ were added to the water samples, and the palladium was extracted and determined using the above developed liquid-liquid extraction method, and the results are listed in Table 3. The standard deviation $(<0.0004)$ and $\%$ RSD $(<2.11)$ indicates that the method was more precise and accurate.

The percentage metal recovery achieved was $>93.33 \%$. The validity of the method was checked by a direct AAS determination of the Pd(II) ion concentration in the synthetic water samples, and the data is listed in Table 3. The data from the present method was close to that determined using AAS, highlighting the validity of this method.

Table 3. $\mathrm{Pd}(\mathrm{II})$ concentration in the synthetic water samples.

\begin{tabular}{cccccc}
\hline $\begin{array}{c}\text { Pd(II) added, } \\
\text { g L }^{-1}\end{array}$ & \multicolumn{2}{c}{ Pd(II) Found, g L $^{-1}$} & S.D & R.S.D. & $\begin{array}{c}\% \\
\text { Recovery }\end{array}$ \\
\cline { 2 - 3 } & Present method & AAS method & & & 98.33 \\
0.012 & 0.0118 & 0.0119 & 0.0002 & 1.69 & 94.66 \\
0.015 & 0.0142 & 0.0145 & 0.0003 & 2.11 & 95.01 \\
0.020 & 0.0190 & 0.0180 & 0.0002 & 1.05 & 98.02 \\
0.025 & 0.0245 & 0.0240 & 0.0004 & 1.63 & 93.33 \\
0.030 & 0.0280 & 0.0290 & 0.0002 & 0.71 & \\
\hline
\end{tabular}

${ }^{*}$ Average of five determinations.

\section{Conclusion}

This study examined the extraction of $\mathrm{Pd}(\mathrm{II})$ from acidic chloride solutions using 4-aroyl3phenyl-5-isoxazalones(HA), such as HPBI, HFBPI and HTPI in chloroform. The extraction strength of the isoxazolones was in the following order: HFBPI > HPBI > HTPI, which correlated with their $\mathrm{p} K_{\mathrm{a}}$ values. The metal extraction strength decreased with increasing $\mathrm{p} K_{\mathrm{a}}$ 
values of the isoxazolones. Interestingly, the substitution of electron-withdrawing fluorine in the fourth position of the benzoyl moiety in the HPBI molecule improved the extraction efficiency of these metal ions. On the other hand, the substitution of electron-releasing groups, such as methyl $\left(-\mathrm{CH}_{3}\right)$ decreased the extraction efficiency, which also reflects their acidity $\left(\mathrm{p} K_{\mathrm{a}}\right.$ ). Loading and striping studies of HPBI were also performed using $1.12 \times 10^{-4} \mathrm{~mol} \mathrm{~L}^{-1}$ $\mathrm{Pd}(\mathrm{II})$ at $0.05 \mathrm{~mol} \mathrm{~L}^{-1}$ as the loading conditions and $1.0 \mathrm{~mol} \mathrm{~L}^{-1} \mathrm{HCl}$ as the striping agent. The maximum metal extraction or desorption was achieved within 3.0 cycles.

The separation of $\mathrm{Pd}(\mathrm{II})$ from $\mathrm{Pt}(\mathrm{IV}), \mathrm{Ni}(\mathrm{II})$ and $\mathrm{Rh}$ (III) acidic chloride solutions was examined as a function of the $\mathrm{H}^{+}$and HPBI concentrations. The calculated separation factors between these metal ions at $0.05 \mathrm{~mol} \mathrm{~L}^{-1} \mathrm{H}^{+}$using HPBI were in the following order: $\mathrm{Pd} / \mathrm{Ni}$ $>\mathrm{Pd} / \mathrm{Pt}>\mathrm{Pd} / \mathrm{Rh}>\mathrm{Rh} / \mathrm{Ni}>\mathrm{Pt} / \mathrm{Ni} \approx \mathrm{Rh} / \mathrm{Pt}$, which correlated with their ionic radius as well as the hard and soft acid base nature of these metal ions. A better separation factor was achieved between $\mathrm{Pd}(\mathrm{II})$ and $\mathrm{Ni}(\mathrm{II})(\mathrm{Pd} / \mathrm{Ni}=40.0)$ metal ions with $\mathrm{HPBI}$.

The above liquid-liquid extraction method was applied successfully to the determination of $\mathrm{Pd}(\mathrm{II})$ from its synthetic water samples and their precision and accuracy was checked by the standard deviation, \% RSD and recovery of metal ion. A comparison of the developed method with a direct determination of $\mathrm{Pd}$ (II) using AAS confirmed that the present method had high accuracy and can be applied successfully to real samples.

\section{Acknowledgment}

This work was supported by Dongguk University Research Grant-2011, Republic of Korea.

\section{References}

1. Matsubara I, Takeda Y and Ishida K, Anal Sci., 2003, 19, 1427.

2. Ravindra.K, Bencs L and Van Grieken R, Sci Total Environ., 2004, 318, 4.

3. Swain B, Jeong J, Kim S and Lee J, Hydrometallurgy., 2010, 104, 1.

4. Brooks C S, “Metal Recovery from Industrial Wastes”, 1991, Lewis Publishers Inc., Chelsea, Michigan., 1986, 21, 267.

5. Hagelüken C, Metall., 2006, 60(1-2), 31 .

6. Hagelüken C, Metall., 2007, 61(1-2), 24.

7. Alam M.S and Inoue K, Hydrometallurgy., 1997, 46, 373-382.

8. Mhaske A A and Dhadke P.M, Hydrometallurgy., 2001, 61, 143-153.

9. Yamini Y, Saleh A and Khajeh M, Sep Purif Technol., 2008, 61, 109.

10. Barakat M A and Mahmoud M H H, Hydrometallurgy., 2004, 72, 179-184.

11. Ritcy G.M and Ashbrook A.W, "Solvent Extraction Principles and Applications to Process Metallurgy Part-1”, 1984, Elsevier Science Publishers B.V, Amsterdam, the Netherlands, 15.

12. Chavan D.V and Dhadke P M, J Sci Ind Res., 2003, 62(8), 834-837.

13. Alguacil F J, Cobo A, Coedo A.A, Dorado M T and Sastre A, Hydrometallurgy, 1997, 44, 203-212.

14. Reddy K.J, Reddy A.V, Shaibu B S and Reddy M L P, Radio Chim Acta, 2007, 95(5), 289-295.

15. Reddy K J, Kumar J R, Reddy M L P, Reddy A V, Hak-Soon P and Kwang-Ho C, Sep Sci Technol., 2009, 44, 2022.

16. Korte F and Storiko K, Chem Ber., 1961, 94, 1956.

17. Pavithran R, Kumar N S S, Biju S, Reddy M L P, Junior A S and Freire R.O, Inorg Chem., 2006, 45, 2184-2192.

18. Reddy M L P and Meera R, Radio Chim Acta, 2001, 89, 453.

19. Pavithran R and Reddy M L P, Radio Chim Acta, 2004, 92, 31-38.

20. Reddy B R, Kumar J R and Reddy A.V, J Braz Chem Soc., 2006, 17, 780-784.

21. Sahu S.K, Chakravortty V, Reddy M L P and Ramamohan T R, Talanta., 2000, 51, 523. 


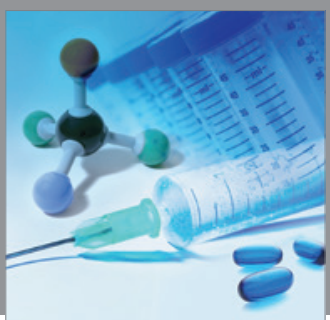

International Journal of

Medicinal Chemistry

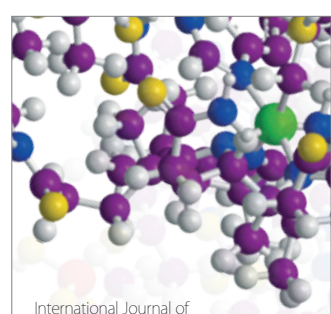

Carbohydrate Chemistry

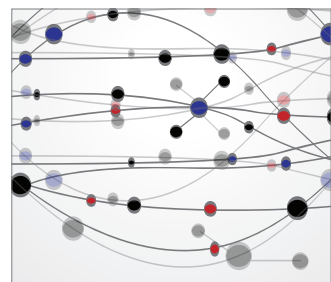

The Scientific World Journal
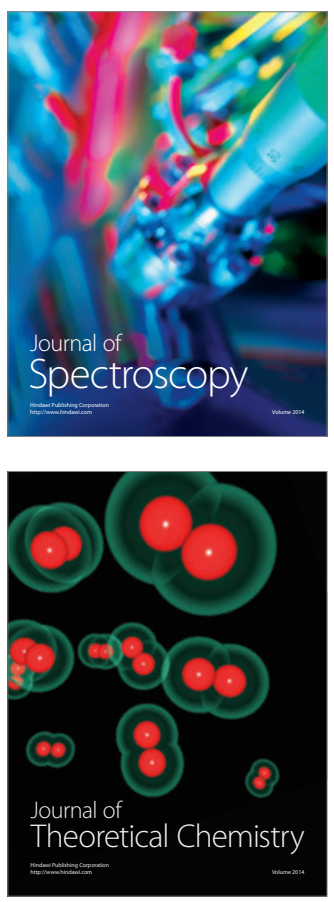
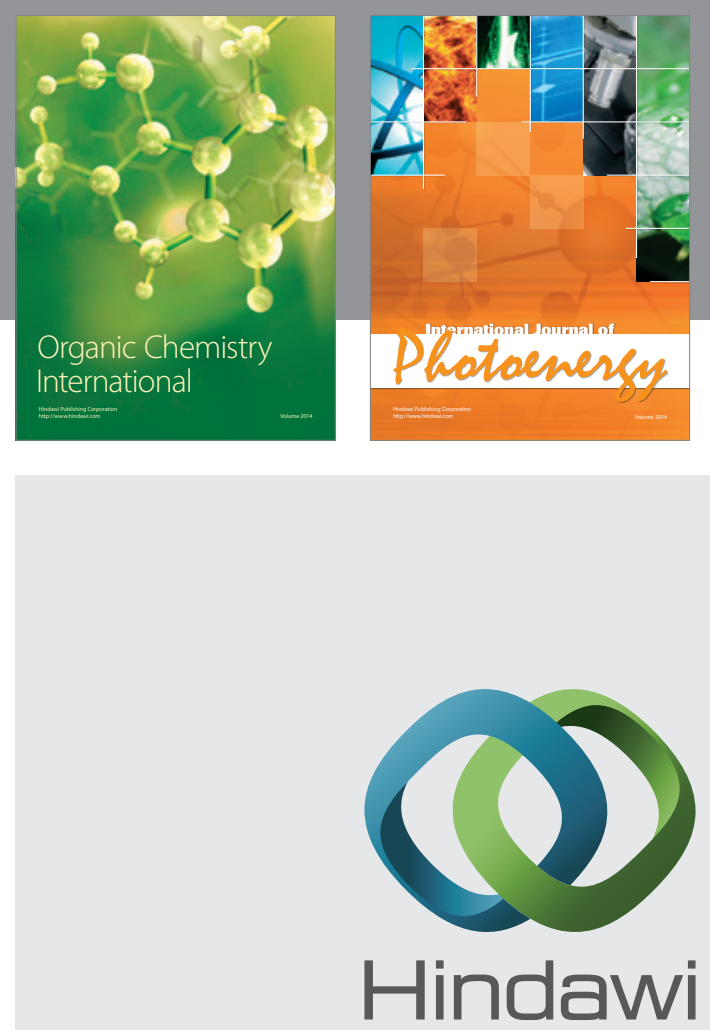

Submit your manuscripts at

http://www.hindawi.com
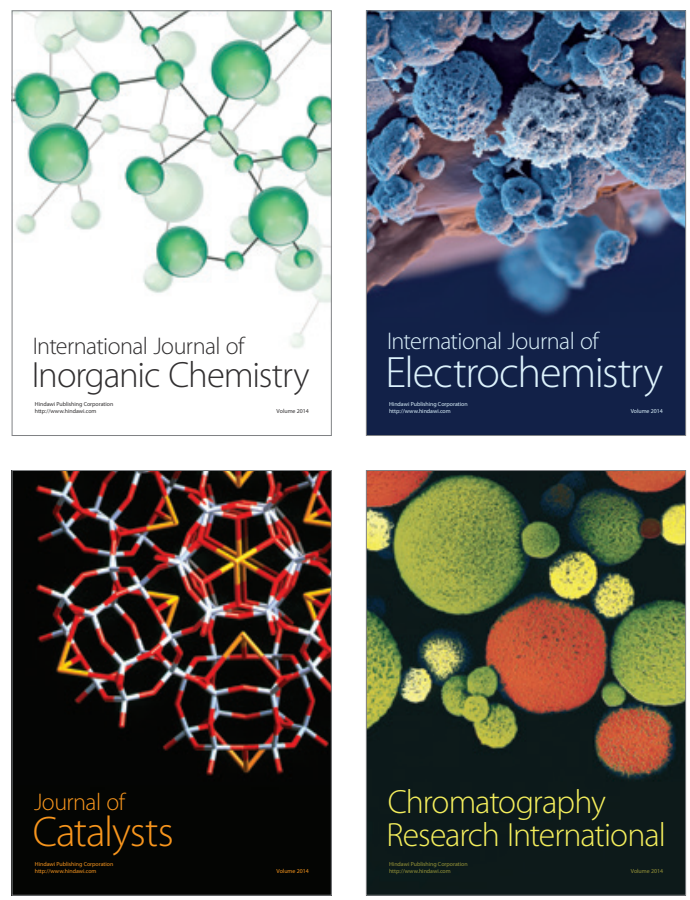
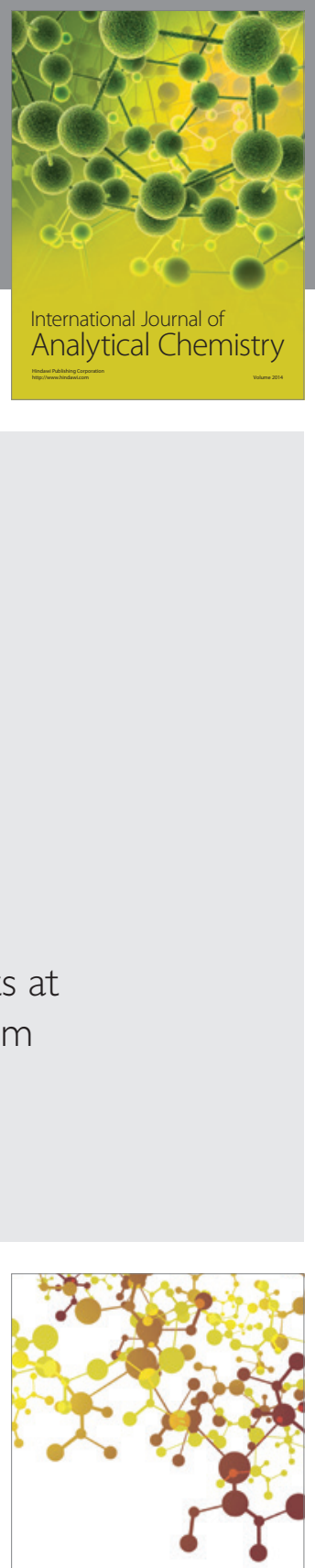

Journal of

Applied Chemistry
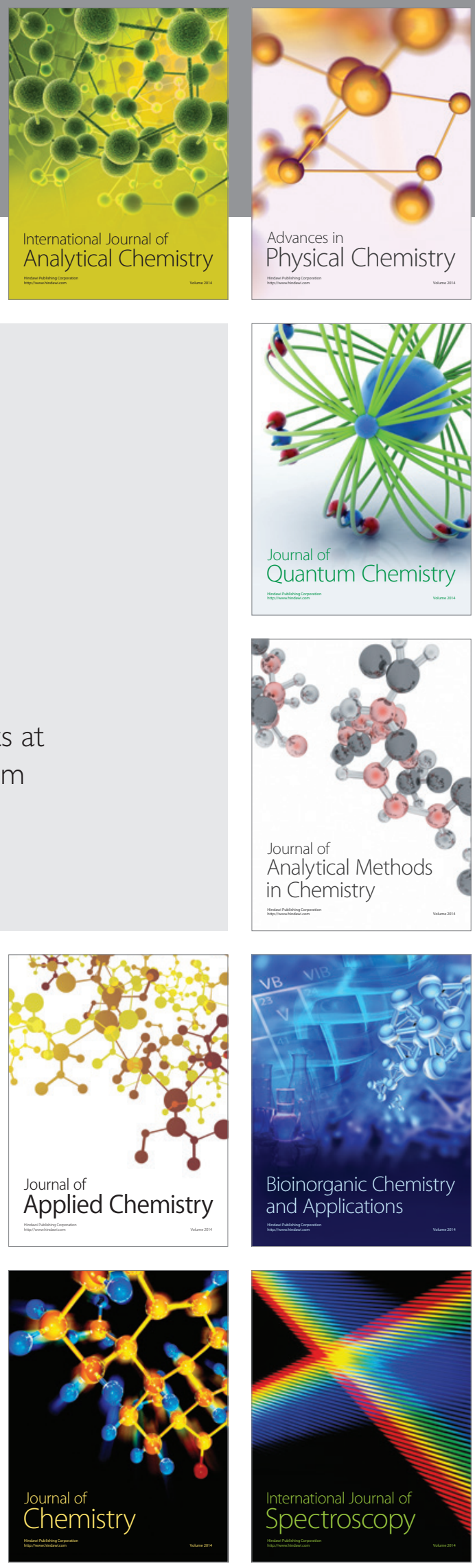